Rev Inv Vet Perú 2021; 32(3): e18901

https://dx.doi.org/10.15381/rivep.v32i3.18901

Comunicación

\title{
Seroprevalencia del virus de inmunodeficiencia felina (VIF) y el virus de la leucemia felina (ViLeF) en gatos del centro de Risaralda, Colombia
}

\author{
Prevalence of feline immunodeficiency virus (FIV) and feline leukaemia virus \\ $(\mathrm{FeLV})$ in cats in the center of Risaralda, Colombia \\ Rafael Santisteban-Arenas ${ }^{1,3}$, Luis Carlos Muñoz-Rodríguez ${ }^{1}$, Julían Díaz Nieto ${ }^{1}$, \\ Valentina Pachón Londoño ${ }^{1}$, Josep Curiel Peña ${ }^{2}$
}

\section{Resumen}

El objetivo del presente estudio fue establecer la seroprevalencia de infección del virus de la leucemia felina (ViLeF) y el virus de la inmunodeficiencia felina (VIF) en muestras séricas de felinos evaluados con sospecha de infección retroviral en centros veterinarios de los municipios de Pereira, Dosquebradas y Santa Rosa de Cabal, departamento de Risaralda, Colombia y enviadas al Laboratorio EjeLab. Se realizó un estudio retrospectivo sobre los resultados de serología con kit comercial para inmunocromatografía (Bionote) entre marzo de 2017 y julio de 2018. Se documentó la edad, raza, sexo de los animales. Se analizaron 388 muestras, siendo el 18.3\% (71) positivas a VIF y el $25.8 \%$ (100) positivo a ViLeF. Se observó coinfección retroviral en el 8.2\% (32) de los animales.

Palabras clave: VIF, ViLeF, retrovirus, felinos

\footnotetext{
${ }^{1}$ Corporación Universitaria Santa Rosa de Cabal, UNISARC, Risaralda, Colombia

${ }^{2}$ Ejelab, Laboratorio Clínico Veterinario, Risaralda, Colombia

${ }^{3}$ E-mail: luis.muñoz@unisarc.edu.co; https://orcid.org/0000-0002-3834-1519
}

Recibido: 13 de octubre de 2020

Aceptado para publicación: 7 de abril de 2021

Publicado: 23 de junio de 2021

(CLos autores. Este artículo es publicado por la Rev Inv Vet Perú de la Facultad de Medicina Veterinaria, Universidad Nacional Mayor de San Marcos. Este es un artículo de acceso abierto, distribuido bajo los términos de la licencia Creative Commons Atribución 4.0 Internacional (CC BY 4.0) [https:// creativecommons.org/licenses/by/4.0/deed.es] que permite el uso, distribución y reproducción en cualquier medio, siempre que la obra original sea debidamente citada de su fuente original 
The aim of this study was to establish the seroprevalence of infection of the feline leukemia virus (ViLeF) and the feline immunodeficiency virus (FIV) in serum samples from felines evaluated with suspected retroviral infection in veterinary centres of the municipalities of Pereira, Dosquebradas and Santa Rosa de Cabal, department of Risaralda, Colombia and sent to the EjeLab Laboratory. A retrospective study was carried out on the results of serology with a commercial kit for immunochromatography (Bionote ${ }^{\circledR}$ ) between March 2017 and July 2018. The age, breed and sex of the animals were documented. In total, 388 samples were analysed, being 18.3\% (71) positive for FIV and 25.8\% (100) positive for ViLeF. Retroviral coinfection was observed in $8.2 \%$ (32) of the animals.

Keywords: FIV, FeLV, retrovirus, feline

\section{INTRODUCCIÓN}

El virus de la leucemia felina (ViLeF) y el virus de la inmunodeficiencia felina (VIF) son organismos que afectan a una amplia población de felinos domésticos a nivel mundial (Little et al., 2020) El ViLeF es un retrovirus, el más patógeno de los dos y causante de neoplasias (especialmente linfoma), aunque también puede causar anemia, inmunosupresión (da Costa et al., 2017; Little et al., 2020), además de ser factor de riesgo para enfermedades inmunomediadas e infecciones secundarias (Little et al., 2020). El VIF es igualmente un retrovirus, causante del síndrome de inmunodeficiencia adquirida, que aumenta el riesgo de infecciones oportunistas, enfermedades neurológicas y tumores en felinos (da Costa et al., 2017). Su trasmisión está más relacionada con mordeduras dado que el virus se encuentra en sangre y saliva. La prevalencia de la infección de ambos retrovirus depende de los lugares de ocurrencia, siendo más más común en animales en condiciones de refugio o calle (Stavisky et $a l ., 2012)$. La información sobre la prevalencia de estos virus en Colombia es escasa, habiendo reportes en ciudades como Montería, Bogotá y Medellín (Tique et al., 2009; Paz, 2016; Molina et al., 2016). Esta información es importante para evaluar el impacto de las políticas públicas de sanidad animal encaminadas a disminuir la presencia de estos patógenos en las poblaciones felinas que, según MINSALUD, en los municipios de Pereira, Dosquebradas y Santa Rosa de Cabal fue de 14247,6950 y 1433, respectivamente, para el primer bimestre del 2015 (MINSALUD, 2016).

Estos últimos municipios se localizan en la región central del eje cafetero, en la cual no existen reportes de la seroprevalencia de la infección retroviral en felinos domésticos. Aunque se desconoce el tamaño exacto de la población de felinos, según el Ministerio de Salud, el número de felinos vacunados en 2015 contra la rabia en los tres municipios indicados fue de 22716 animales, cifras que suelen ser empleadas para estimar la población de felinos, ya que los reportes de vacunación de rabia son obligatorios por ley y de común acceso. Esta población está expuesta al riesgo de infección retroviral y los médicos veterinarios necesitan información actualizada de la prevalencia de estas enfermedades para estimar el riesgo y generar estrategias de prevención y tratamiento. El presente trabajo tuvo como objetivo la realización de un estudio serológico retrospectivo con el fin de identificar la prevalencia del virus de Inmunodeficiencia Felina (VIF) y el virus de la Leucemia Felina (ViLeF) en tres municipios del departamento de Risaralda. 


\section{Materiales y Métodos}

Se realizó un estudio retrospectivo que incluyó los datos de muestras serológicas de felinos domésticos enviadas por clínicas veterinarias al laboratorio EJELAB en Pereira, Risaralda, Colombia, para exámenes de inmunocromatografía comercial de FIV Ab/ FeLV Ag Test Kit (Bionote ${ }^{\grave{\text { }}}$ ) entre marzo de 2017 a julio de 2018. Las muestras de los felinos fueron obtenidas en los municipios de Pereira, Dosquebradas y Santa Rosa de Cabal, pertenecientes al departamento de Risaralda en las clínicas que remitieron las muestras y fueron analizadas siguiendo las instrucciones del fabricante.

El análisis estadístico fue realizado con el software JASP Team 2020 (JASP v. $0.14 .1)$. Se consideraron como variables para el análisis estadístico la raza, sexo, edad (111 meses, 1-3 años, 4-8 años, y $>9$ años) y seropositividad a VIF y ViLeF. Se formaron tres grupos según su estado retroviral: seropositivos a VIF o ViLeF, seronegativos, y seropositivos a ambos virus (coinfección). Además, se colectó información referida a variables hematológicas como hematocrito, leucocitos totales y diferenciados, creatinina y ALT de aquellos animales que tuvieran estos datos en estado de coinfección. Todas las variables cuantitativas se resumieron con promedio y desviación estándar y se determinaron las prevalencias a cada virus, así como los porcentajes de coinfección. Las variables sexo y seropositividad se tabularon en tablas de contingencia y se analizaron con la prueba de Chi cuadrado, así como el Odds Ratio.

Para determinar el tamaño de muestra se consideró el tamaño de la población (22716 felinos según MINSALUD [2016]) en los tres
Cuadro 1. Seroprevalencia del virus de la leucemia felina (ViLeF) y el virus de la inmunodeficiencia felina (VIF)

\begin{tabular}{lcc}
\hline & Positivos & Negativos \\
\hline VIF & $71(18.3 \%)$ & 317 \\
ViLeF & $100(25.8 \%)$ & 288 \\
VIF + ViLeF & $32(8.2)$ & \\
\hline
\end{tabular}

municipios, $5 \%$ de margen de error y un intervalo de confianza del $95 \%$, resultando en un tamaño de muestra mínimo de 378 animales.

\section{Resultados}

En el periodo analizado se procesaron 388 pruebas de inmunocromatografía para VIF Y ViLeF en muestras de sangre de felinos domésticos, obteniéndose una seroprevalencia de $25.8 \%(100 / 388)$ para leucemia felina, $18.3 \%$ (71/388) para inmunodeficiencia felina y una coinfección de VIF e ViLeF de $8.2 \%$ (32/388) (Cuadro 1). El porcentaje de animales seronegativos fue de $64 \%$ (249/388).

Entre los animales muestreados, 366 fueron clasificados como mestizos, 14 persas, 2 Siamés, 1 Bombay, 1 Exótico, 1 Sphynx, 1 Bengalí y 2 no tenían registro de raza. Así mismo, la distribución y seroprevalencia por sexo y grupos etarios se muestra en el Cuadro 2 .

La proporción de machos y hembras entre los grupos seropositivos y seronegativos de VIF y ViLef fue significativamente diferente, ya que existe una relación entre la variable sexo y la seropositividad a VIF (Chi cuadrado 23.52, $\mathrm{p}<0.001$ ) y la seropositividad de ViLef (Chi cuadrado 23.52, $\mathrm{p}=0.002$ ). 
Cuadro 2. Seroprevalencia del virus de la leucemia felina (ViLeF) y el virus de la inmunodeficiencia felina (VIF) según sexo y grupos etarios en felinos domésticos en tres distritos de

\begin{tabular}{|c|c|c|c|c|c|}
\hline \multirow{2}{*}{\multicolumn{2}{|c|}{$\overline{\text { Sexo }}$}} & \multirow[t]{2}{*}{$\begin{array}{c}\text { Población } \\
\text { (n) }\end{array}$} & \multicolumn{3}{|c|}{$\begin{array}{l}\text { Seropositivos } \\
\text { (n) }\end{array}$} \\
\hline & & & ViLeF & VIF & Coinfección \\
\hline & Hembras & 146 & 25 & 9 & 4 \\
\hline & Machos & 237 & 73 & 61 & 27 \\
\hline & No determinado & 7 & 2 & 1 & 1 \\
\hline \multicolumn{6}{|c|}{ Edad } \\
\hline & Cachorros & 68 & 5 & 1 & 0 \\
\hline & Jóvenes & 96 & 32 & 15 & 8 \\
\hline & Adultos & 66 & 18 & 15 & 5 \\
\hline & Gerontes & 13 & 3 & 4 & 2 \\
\hline & Indefinida & 145 & 42 & 36 & 17 \\
\hline Total & & 388 & 100 & 71 & 32 \\
\hline
\end{tabular}

\section{Discusión}

La seroprevalencia encontrada para ViLeF fue del $25.8 \%$, siendo mayor al $13.1 \%$ de gatos positivos a ViLeF reportado por Collazos (2016) en Bogotá y al 23.3\% reportado por Tique et al. (2009) en Montería. La seroprevalencia de VIF fue establecida en $18.3 \%$, cifra similar a la reportada por Collazos (2016) quién reportó $11.4 \%$ de seroprevalencia para VIF, en tanto que Molina et al. (2016) reportaron $10.7 \%$ y Tique et al. (2009) reportó 1.6\%. Estas diferencias podrían deberse a que las muestras del presente estudio fueron tomadas a felinos con sospecha de infección retroviral. En el presente estudio se observó una seroprevalencia de coinfección de $8.2 \%$, valor superior al $5 \%$ $(\mathrm{n}=66)$ reportada en Montería (Tique et al., 2009) e n Montería. Así mismo, Westman et al. (2016) en Australia reportaron una seroprevalencia a coinfección del $0.5 \%$ en una población muestreada de 2083 gatos.

Estudios en Argentina y Brasil se reportan prevalencias variables de ViLeF y VIF. Galdo Novo et al. (2017) en Buenos Aires, Argentina, determinaron mediante PCR sobre una muestra de 255 felinos una prevalencia para VIF de $20.3 \%$ y para ViLeF de $11.82 \%$, en tanto que Luckman y Carolyn (2017) en Nueva Zelanda encontró una seroprevalencia de ViLeF Y VIF de 2.6 y $18.5 \%$ respectivamente. En la presente investigación se encontró una asociación entre el sexo y la seropositividad, demostrando que los machos tienen mayores probabilidades de contagio. Esto concuerda con diversos reportes y puede estar relacionado con el comportamiento propio de los machos y peleas territoriales que pueden incrementar la probabilidad de contagio (Levy et al., 2008; Beatty et al., 2011; Luckman y Gates, 2017). 
Los gatos mestizos tuvieron mayor probabilidad de infección que los gatos de raza, sin embargo, el escaso número de gatos de raza (17/388), los resultados sobre el componente racial tienen poca relevancia. El resultado respecto a la edad concuerda con los estudios de Costa et al. (2017) y Poffo et al. (2017) en Brasil, quienes afirman que los gatos jóvenes tienen más probabilidades de ser seropositivos que los gatos adultos en ambas enfermedades, a diferencia del reporte de Sivagurunathan et al. (2018), donde concluyen que los gatos adultos tienen un estado seropositivo más alto.

\section{Conclusiones}

Las seroprevalencias del virus de la leucemia felina (ViLeF) y el virus de la inmunodeficiencia felina (VIF) en felinos sospechosos de infección retroviral evaluados en consulta veterinaria en los municipios de Pereira, Dosquebradas y Santa Rosa de Cabal fue de 25.8 y de $18.3 \%$, respectivamente y de $8.2 \%$ para los casos de coinfección.

\section{Literatura Citada}

1. Beatty JA, Tasker S, Jarrett O, Lam A, Gibson S, Noe-Nordberg A,Pjillips A, et al. 2011. Markers of feline leukaemia virus infection or exposure in cats from a region of low seroprevalence. J Feline Med Surg 13: 927-33. doi: 10.1016/j.jfms.2011.07.011

2. Da Costa FVA, Valle SDF, Machado G, Corbellini LG, Coelho EM, Rosa RB., González FHD. 2017. Hematological findings and factors associated with feline leukemia virus (FeLV) and feline immunodeficiency virus (FIV ) positivity in cats from southern Brazil. Pesq Vet Bras 37: 1531-1536. doi: 10.1590/S0100-736X2017001200028
3. Galdo Novo S, Bucafusco D, Diaz LM, Bratanich AC. 2016. Viral diagnostic criteria for Feline immunodeficiency virus and Feline leukemia virus infections in domestic cats from Buenos Aires, Argentina. Rev Argent Microbiol 48: 293-297. doi: 10.1016/j.ram.2016.07.003

4. Levy J, Crawford C, Hartmann K, Hofmann-Lehmann $R$, Little $S$, Sundahl E, Thayer V. 2008. American Association of Feline Practitioners' feline retrovirus management guidelines. J Feline Med Surg 10: 300-316. doi: 10.1016/j.jfms.2008.03.002

5. Little S, Levy J, Hartmann $K$, Hofmann-Lehmann R, Hosie M, Olah G, Denis KS. 2020. AAFP feline retrovirus testing and management guidelines. J Feline Med Surg 22: 5-30. doi: 10.1177/1098612X19895940

6. Luckman C, Gates MC. 2017. Epidemiology and clinical outcomes of feline immunodeficiency virus and feline leukaemia virus in client-owned cats in New Zealand. JFMS Open Rep 3(2): 2055116917729311. doi: 10.1177/ 2055116917729311

7. [MINSALUD] Ministerio de Salud. 2016. Cobertura de vacunación antirrábica de perros y gatos por municipio en Colombia.

8. Molina VM, Blanco RD, Estepa P, Tamayo S. 2016. Frecuencia del virus de inmunodeficiencia felina (VIF) enel sur del Valle de Aburrá, Colombia ( 2013-2015 ). Rev Científ FCV-LUZ 26: 374-378.

9. Paz M. 2016. Coinfección y hallazgos epidemiológicos de los virus de inmunodeficiencia felina (VIF) y leucemia felina (VILEF) en gatos clínicamente enfermos. Tesis de Maestría. Bogotá, Colombia: Pontificia Univ. Javeriana. $39 \mathrm{p}$

10. Poffo D, Almeida ABPF, Nakazato L, Dutra V, Correa SHR, Mendonça AJ, Sousa VRF. 2017. Feline immunodeficiency virus (FIV), feline leukaemia virus (FeLV) and Leishmania sp. in 
domestic cats in the Midwest of Brazil. Pesq Vet Bras 37: 491-494. doi: 10.1590/ S0100-736X2017000500011

11. Sivagurunathan A, Atwa AM, Lobetti R. 2018. Prevalence of feline immunodeficiency virus and feline leukaemia virus infection in Malaysia: a retrospective study. JFMS Open Rep 4(1): 2055 11691775258. doi: 10.1177/2055116917752587
12. Stavisky J, Dean RS, Molloy MH, Stavisky J, Molloy MH, Bvs BVM. 2012. Prevalence of and risk factors for FIV and FeLV infection in two shelters in the United. Vet Rec 181(17): 451. doi: 10.1136/vr.103857

13. Tique V, Sánchez A, Álvarez L, Ríos $R$, Mattar S. 2009. Seroprevalencia del virus de leucemia e inmunodeficiencia felina en gatos de Montería, Córdoba. Rev Med Vet Zoot 56: 85-94. 